\title{
Consecutive measurements show association of IGF-1 with preterm delivery in type 1 diabetic pregnancy
}

\author{
Finn F Lauszus ${ }^{1 *}$, Ingvild H Tjessem ${ }^{1}$, Rebekka O Svarrer ${ }^{1}$ and Hanine MF Al-Far ${ }^{1}$ \\ ${ }^{1}$ Department of Gynecology and Obstetrics, Herning Hospital, Denmark
}

\begin{abstract}
Aim: Few data on insulin-like growth factor 1 (IGF-1) and preterm delivery are reported in type 1 diabetes mellitus while cross-sectional studies with regulators of IGF-1 indicate association with preterm delivery and fetal growth. We evaluated time-course relationship between the maternal serum IGF-1 and the subsequent obstetrical outcome.

Setting and design: Consecutive follow-up study of 130 pregnant women with type 1 diabetes recruited for measurement of growth factors and evaluated for diabetes status and adverse perinatal outcome. Serum was drawn for measurement of IGF-1 at every fourth week during pregnancy until week 30, then every second week. Preterm was defined as delivery before week 36 . Arterial stiffness index was calculated from diurnal blood pressure measurements. Birth weight was adjusted for gender and gestational age by calculating a birth weight ratio.

Results: Diabetic women who delivered preterm had lower IGF-1 levels throughout pregnancy. Measured consecutively with all data present, IGF-1 in week 14 to 32 was consistently lower compared with women who delivered after gestational week 35 adjusted for albumin excretion rate preeclampsia, arterial stiffness index, duration of diabetes, and parity $(\mathrm{p}<0.05)$. Low birth weight in terms of birth weight ratio $(<1.22)$ was associated with lower IGF-1 from week 14 to 32 ; also, when adjusted for preterm delivery, albumin excretion rate, and preeclampsia $(\mathrm{p}<0.05)$. Birth weight ratio was higher in women delivering preterm compared to women
\end{abstract} delivering at term.

Conclusion: Preterm delivery showed an association with consecutive IGF-1 values from week 14 to 32 . Fetal growth was not impeded in preterm delivery in diabetic pregnancy.

Key message: In diabetic pregnancy, low levels of IGF-1 are independently associated with preterm delivery and low birth weight.

Abbreviations: AER: Albumin Excretion Rate, ANOVA: Analysis of Variance, AASI: Ambulatory Arterial Stiffness Index, IGF-1: Insulinlike Growth Factor-1, PAPP-A: Pregnancy-associated Protein-A, SGA: Small-for-Gestational-Age

The massive cross-sectional data on preterm delivery in nondiabetic pregnancies leaves no doubt that biological markers may help in prediction in populations with variable background risks. In diabetes, in particular, growth restricting and promoting factors are present at the same time pointing to the importance of the timing of when adverse effects are initiated and exerting influence on maternal and fetal outcome. Potential candidates for biomarkers for adverse obstetric outcomes in women with type 1 diabetes involve various organ systems, markers of vascular function, insulin resistance, and glucose intolerance. Insulin-like growth factor 1 (IGF-1) acts in a number of tissues through endocrine, paracrine, and autocrine pathways and is partially bound to binding proteins and regulated by growthhormone. In addition to IGF-1's mitogenic properties regulating cellular proliferation, it acts through a IGF-receptor on the placenta regulating some of the passage of substrate to the fetus $[1,2]$. During pregnancy, proteolysis, glycosylation, and phosphorylation modulate the maternal level of IGF-1. In $1^{\text {st }}$ to $2^{\text {nd }}$ trimester pregnancy-associated protein-A (PAPP-A) is prominently involved in IGF regulation through proteolysis and is associated with obstetrical outcome like preterm delivery, preeclampsia, and with neonates who are small-forgestational age (SGA) and growth restricted [3-8].
Women with type 1 diabetes mellitus deliver preterm at much higher rates than non-diabetic women and in case of nephropathy the incidence is nearly $50 \%$ [9-11]. Thus, important comorbidities are factors for the preterm delivery in diabetes, i.e. glycemic malregulation, increased albumin excretion in urine, and retinopathy have shown associations with preterm delivery. Early onset of labor or premature rupture of membranes are among the conditions that lead to delivering preterm; however, background variables like preeclampsia and hypertensive complications are more common. The latter is easily detectable but antihypertensive treatment is mainly symptomatic to gain time and advance gestation before delivery [12]. Preterm delivery poses significant risk in diabetic pregnancy affecting fetal growth, too, and the causative pathways are poorly described.

The aim of the present study was to investigate the time-course relationship between the maternal serum IGF-1 and the subsequent obstetrical outcome in diabetic pregnancies with various levels of background risk. Accordingly, we included pregnancies of women with different levels of albumin excretion rate (AER) and preeclampsia.

Correspondence to: Finn Friis Lauszus, senior consultant, Department of Gynecology and Obstetrics, Herning Hospital, Gl. Landevej 61, DK-7400 Herning, Denmark, Tel: +45 784236 14; Fax: +45 7843 46 36; E-mail: finlau@rm.dk

Key words: IGF-1, preeclampsia, preterm delivery, type 1 diabetes mellitus, birth weight

Received: April 02, 2017; Accepted: May 01, 2017; Published: May 04, 2017 


\section{Methods}

154 pregnant women with type 1 diabetes were consecutively recruited for measurement of growth factors, evaluated for deterioration of diabetes status, and adverse perinatal outcome. The study was part of an evaluation of nephropathy and retinopathy, approved by the local Ethical Committee (jr. nr. 1992/2523, 1998/4147, and 2026-99) and performed in concordance with the Helsinki II declaration. All women gave their informed consent. Blood samples were drawn from week 6 and every $4^{\text {th }}$ week until week 30 , then every $2^{\text {nd }}$ week. From all participating women sufficient clinical data was gathered several times each trimester on insulin dose, $\mathrm{HbAlc}$, weekly glucose measurements and 24-h urine albumin excretion. No woman had a history of or delivered due to cervical incompetence, and only pregnancies with delivery after gestational week 32 are presented. Complete blood sample measurements from week 14 to 32 were available in 130 women. Of the 24 excluded women 19 had incomplete sampling and five delivered before week 32 and, thus, our study group comprised of 130/149 (87\%) of the eligible women.

Preterm delivery was defined as delivery before 36 weeks of gestation. A birth weight ratio was computed by dividing the observed birth weight with the expected birth weight for the same gestational age and gender (50\% percentile). The expected weights were calculated and distributed by the Danish Health and Medicines Authority [13]. The birth weight ratio was grouped into tertiles for analysis of association with repeated measurements of IGF-1. The range of tertiles was 0.8 $1.21,1.22-1.44$, and $1.45-2.1$. The reason to split the birth weight into tertiles was to detect growth inhibition in the cohort; the birth weight distribution being non-Gaussian and shifting towards macrosomia. The department's policy on deliveries in type 1 diabetes was to induce delivery in week 37-38 and all women were instructed to measure frequent glucose at home and administrating insulin 4-6 times daily, aiming at normoglycemia with $\mathrm{HbAlc}$ ranging from 4.3 to $6.5 \%$.

Diurnal blood pressure (BP) was measured in every trimester and after delivery with a portable monitor (SpaceLab 90207; Redmond, WA). The ambulatory arterial stiffness index (AASI) was calculated to detect vasculopathy. AASI was defined as one minus the regression slope of diastolic BP on systolic BP from the diurnal recording. This was performed successfully in 96 of the 130 women. Preeclampsia is defined as increased BP of $140 / 90 \mathrm{mmHg}$ or greater and albuminuria in excess of $300 \mathrm{mg}$. Preeclampsia was defined as systole / diastole BP of $140 / 90 \mathrm{mmHg}$ or greater for individuals who were normohypertensive before week 20 and, concomitantly, albuminuria in excess of $300 \mathrm{mg}$ per day in previously normoalbuminuric women. AER was measured by 24 -h collection of urine and grouped into normo- $(<30 \mathrm{~g} / 24 \mathrm{~h})$, micro- (30-299 g/24h) and macroalbuminuria ( $>300 \mathrm{~g} / 24 \mathrm{~h})$. Insulin dose was registered for every second gestational week until week 32 , hereafter it was noted weekly.

\section{Statistical analysis}

Statistics was performed with IBM SPSS statistics 20. Difference between two means was tested with Student's t-test if data followed Gaussian distribution; otherwise Mann-Whitney's test was used. For evaluation of proportions, Fishers Exact Probability test for $2 \times 2$ and $2 \times 3$ tables were used. The variable AER was normalized by logarithm computing. Comparison of the difference between means was tested with analysis of variance (ANOVA); if non-Gaussian distributed, Kruskal-Wallis' test was used. Newman-Keul's post-hoc test was applied when the ANOVA test was $\mathrm{p}<0.05$. Linear regression analysis was performed with IGF-1 as dependent variable and as independent variables preeclampsia, AER, HbA1c, insulin dose per kg body weight, age, duration of diabetes, birth weight ratio, and BMI. Repeated measures analysis of variance (two-way-ANOVA) was used for comparison of IGF-1 taken over time with preterm delivery as group variable and covariants were added; first, duration of diabetes and parity was added and then preeclampsia, AASI and AER. The reason to do separately analysis is that the former constitute static personal characteristics while the other mirrors physiologic dynamics of pregnancy. Finally, all were added to the model. Similarly, IGF-1 as dependent variable and birth weight tertiles as group variable and, further, insulin per body weight as dependent variable and preterm delivery as group variable were evaluated with two-way-ANOVA. Values are given as mean \pm $\mathrm{SD}$ if Gaussian distributed and, if otherwise, stated as median (range). A two-sided p-value of 0.05 was the level of significance. IBM SPSS Statistics 20 was used as the statistical software.

\section{Serum total IGF-I}

Serum total IGF-I was measured with a noncompetitive timeresolved immunofluorometric assay based on monoclonal antibodies and performed in micro test wells [14]. IGF-I antibodies were immobilized on the solid matrix and the detection limit was 0.0025 $\mathrm{mg} / \mathrm{l}$ for the IGF-I assay. The operating range included upwards of $2.5 \mathrm{mg} / \mathrm{l}$ (IGF-I). All clinically relevant serum concentrations could be measured in one final dilution (1:1,066 for IGF-I) after ethanol extraction. The inter-assay variation was $<10 \%$. Samples for IGF-I were drawn at gestational weeks $6,10,14,18,22,26,30,32,34,36$, and 38 and in the women who came for check-up 3-6 months postpartum. In total 870 of 910 (96\%) possible blood samples were obtained from weeks 6-34. Blood samples were measured in 29\%, 58\%, 92\%, and 35\% of possible samples in week $6,10,34$, and post partum, respectively.

\section{Results}

Of 37 preterm deliveries $38 \%$ were due to preeclampsia and $30 \%$ $(n=11)$ due to premature rupture of membranes. Further etiologies of preterm delivery occurred in less than $<5 \%$ of the women. Thus, three women delivered in week 32, seven women in week 33,11 in week 34 , and 18 in week 35 (Table 1). The birth weight was different in women with respect to delivery; when adjusting for gender and gestational age the preterm neonates were larger than those delivered at term (Table 1). Both groups of women had larger babies than the background population whose birth weight ratio by definition is 1.0.

Diabetic women who delivered preterm had lower IGF-1 levels throughout pregnancy (Table 2). Measured consecutively with all data present, IGF-1 in week 14 to 32 was consistently lower compared with women whose delivered after gestational week 35 ( $\mathrm{p}=0.049$ ); also, when adjusting for albumin excretion rate, AASI, and preeclampsia $(p=0.045)$ or duration of diabetes and parity $(p=0.049$, Figure 1$)$ Adding all covariants, the association persisted $(\mathrm{p}=0.05)$.

Low birth weight in terms of birth weight ratio (0.8-1.22) was associated with lower IGF-1 from week 14 to 32 (two-way-ANOVA, lowest vs. middle and highest tertile, $\mathrm{p}=0.046$ ); also, when adjusted for preterm delivery, albumin excretion rate, and preeclampsia $(\mathrm{p}=0.038)$. In normoalbuminuric women alone similar significant results were found $(p=0.033)$. Regression analysis showed an association of higher IGF-1 with high birth weight ratio from week 26 to 34 (week 26,30,32,34; all $\mathrm{p}<0.05)$.

Insulin dose per kg body weight was simiar throughout pregnancy in preterm delivering women compared to women delivering at term with similar glycemic levels and did not reach the level of significance 
Table 1. Clinical data in 130 women with type 1 diabetes by delivery and albumin excretion.

\begin{tabular}{|c|c|c|c|c|c|c|c|}
\hline & $\begin{array}{c}\text { Women delivering } \\
\text { preterm }\end{array}$ & $\begin{array}{c}\text { Women delivering } \\
\text { at term }\end{array}$ & $\begin{array}{c}\text { p-value } \\
\text { preterm vs. term }\end{array}$ & $\begin{array}{c}\text { Normo- } \\
\text { albuminuric } \\
\text { women }\end{array}$ & $\begin{array}{c}\text { Micro-albuminuric } \\
\text { women }\end{array}$ & $\begin{array}{c}\text { Macro- } \\
\text { albuminuric } \\
\text { women }\end{array}$ & $\begin{array}{c}\text { p-value } \\
\text { AER groups } \\
\text { ANOVA }\end{array}$ \\
\hline No. & 37 & 93 & & 107 & 15 & 8 & \\
\hline Age & $27 \pm 4$ & $28 \pm 4$ & 0.28 & $28 \pm 4$ & $27 \pm 4$ & $30 \pm 4$ & 0.41 \\
\hline Onset of diabetes (yrs)\# & $14(1,33)$ & $17(1,36)$ & $0.17 \#$ & $17(2,29)$ & $13(2,29)$ & $10(1,18)$ & $0.01 \#$ \\
\hline Duration of diabetes (yrs) & $13 \pm 8$ & $12 \pm 8$ & 0.48 & $11 \pm 8$ & $14 \pm 7$ & $20 \pm 5$ & 0.007 \\
\hline Parity & $1.6 \pm 0.9$ & $1.8 \pm 1$ & 0.13 & $1.8 \pm 1$ & $1.8 \pm 1$ & $1.8 \pm 1$ & 0.99 \\
\hline HbA1c $1^{\text {st }}(\%)$ & $7.7 \pm 1.1$ & $7.3 \pm 1$ & 0.17 & $7.3 \pm 1$ & $7.9 \pm 1$ & $8.1 \pm 1.2$ & 0.043 \\
\hline Clearance $1^{\text {st }}(\mathrm{ml} / \mathrm{min})$ & $123 \pm 26$ & $129 \pm 27$ & 0.14 & $129 \pm 26$ & $126 \pm 30$ & $109 \pm 22$ & 0.21 \\
\hline Systolic BP $1^{\text {st }}(\mathrm{mmHg})$ & $121 \pm 9$ & $119 \pm 9$ & 0.44 & $117 \pm 8$ & $126 \pm 6$ & $133 \pm 9$ & 0.001 \\
\hline Diastolic BP $1^{\text {st }}(\mathrm{mmHg})$ & $74 \pm 7$ & $71 \pm 6$ & 0.11 & $70 \pm 6$ & $76 \pm 4$ & $81 \pm 5$ & 0.001 \\
\hline AASI & $0.33 \pm 0.15$ & $0.3 \pm 0.17$ & 0.54 & $0.29 \pm 0.17$ & $0.36 \pm 0.15$ & $0.4 \pm 0.15$ & 0.12 \\
\hline Gestational week & $34.1 \pm 1$ & $36.7 \pm 0.8$ & 0.001 & $36.6 \pm 1.4$ & $35.8 \pm 1.7$ & $35.1 \pm 1.5$ & 0.23 \\
\hline Birth weight $(\mathrm{g})$ & $3357 \pm 695$ & $3857 \pm 635$ & 0.001 & $3814 \pm 638$ & $3380 \pm 673$ & $3010 \pm 837$ & 0.001 \\
\hline Birth weight ratio & $1.45 \pm 0.3$ & $1.3 \pm 0.23$ & 0.003 & $1.38 \pm 0.25$ & $1.2 \pm 0.2$ & $1.13 \pm 0.21$ & 0.002 \\
\hline Lowest birth weight tertile No. (\%) & $8(22)$ & $35(38)$ & $0.1^{*}$ & $31(29)$ & $8(53)$ & $4(50)$ & $0.11^{*}$ \\
\hline Preeclampsia in no. & 14 & 13 & $0.004 *$ & 20 & 4 & 3 & $0.26^{*}$ \\
\hline $\begin{array}{l}\text { Preterm delivery in no. (no. with } \\
\text { preeclampsia) }\end{array}$ & $37(14)$ & - & & $27(9)$ & $5(3)$ & $5(3)$ & $0.08^{*}$ \\
\hline
\end{tabular}

AER: Albumin excretion rate, BP: Blood pressure $(24 \mathrm{~h})$, AASI: Ambulatory arterial stiffness index.

$1^{\text {st: }}$ First trimester. \#: data are non-Gaussian, p-value after Mann-Whitney and Kruskal-Wallis test, respectively, *: Fisher's Exact test

Table 2. IGF-1 during pregnancy in 130 women with type 1 diabetes.

\begin{tabular}{|c|c|c|c|}
\hline & $\begin{array}{c}\text { Women delivering } \\
\text { preterm }\end{array}$ & $\begin{array}{c}\text { Women delivering } \\
\text { term }\end{array}$ & $\begin{array}{c}\text { p-value } \\
\text { preterm vs. term }\end{array}$ \\
\hline No. & 37 & 93 & \\
\hline Week 6 $(\mathrm{n}=40)$ & $100 \pm 29$ & $102 \pm 33$ & 0.82 \\
\hline Week 10 (n=81) & $84 \pm 22$ & $97 \pm 28$ & 0.042 \\
\hline Week 14 & $88 \pm 25$ & $96 \pm 36$ & 0.22 \\
\hline Week 18 & $82 \pm 24$ & $96 \pm 37$ & 0.044 \\
\hline Week 22 & $85 \pm 28$ & $97 \pm 40$ & 0.08 \\
\hline Week 26 & $102 \pm 40$ & $121 \pm 69$ & 0.12 \\
\hline Week 30\# & $129(19,253)$ & $139(30,713)$ & $0.24 \#$ \\
\hline Week 32\# & $131(17,306)$ & $148(41,593)$ & $0.58 \#$ \\
\hline Week 34 (n=113)\# & $157(70,282)$ & $159(33,534)$ & $0.37 \#$ \\
\hline Week 36 (n=80) & & $186 \pm 86$ & \\
\hline Week 38 (n=16) & & $148 \pm 38$ & \\
\hline 3 months post & $109 \pm 41$ & $115 \pm 37$ & 0.58 \\
\hline partum (n=48) & & & \\
\hline
\end{tabular}

IGF-1 in mg/l, \#: data are non-Gaussian distributed, p-values after Mann-Whitney test

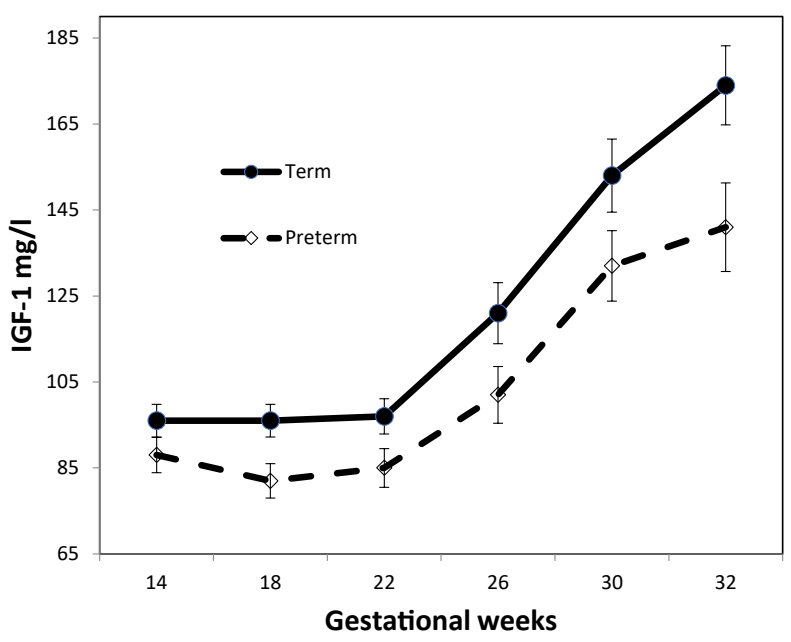

Covariates appearing in the model were evaluated at the following values: Duration $=12.17$, parity 1.82 . IGF-1 are given as mean \pm SEM

Figure 1. IGF-1 in 130 women with type 1 diabetes from gestational week 14 to 32 .
(Figure 2, $\mathrm{p}=0.48$ ); however, in a limited time from week 14 to 30 the daily insulin dose per $\mathrm{kg}$ body weight rose significantly more in women delivering preterm than in those delivering at term, adjusting for duration of diabetes, parity, and AASI $(\mathrm{p}=0.036)$.

\section{Discussion}

The main finding of our study is the time course association of lower IGF-1 with preterm delivery also when AER and preeclampsia are taken into account. This is in line with several large cross-sectional data from non-diabetic women, who delivered preterm and had SGA neonates (3-8). PAPP-A was attributed to play a role as early as in gestational week 10-14 in prediction of these adverse events. The lower PAPP-A levels result in less proteolysis of the IGF binding proteins and subsequently less bioavailable IGF-1. We corroborate these in our consecutive series of IGF-1 measurements and present a potential link during time of pregnancy replacing a prevalence measurement early in pregnancy. We did, however, find cross-sectional differences of IGF-1 in week 10 and 18 (Table 2), similar to the sampling times in the former studies on PAPP-A (3-8). The outcomes need to be further elucidated for the factors, which are working in concert with or mediating the downstream effects $[6,8,15]$.

Our limitations are mainly in the number of women we had to exclude to achieve complete data; however, the massive consecutive collection on biochemical data, home measurements and diaries on glycemia and insulin, AER, blood pressure data and evaluation throughout pregnancy ensure that we most likely did not miss any confounders in vasculopathy and other diabetes related factors. We included the stiffness index, similar to AER, to be able to quantitate vascular morbidity in a continuous variable. We are, therefore, confident that we describe the true direction of the association in a high-risk population with sufficient clinical data to highlight the potential mechanisms. We excluded deliberately several very preterm deliveries in our restriction criteria as a trade off for complete sampling data. By this we have only limited potential causes for early delivery in our study, which may limit its validity. Concurrently the prevalence of preeclampsia may be higher due to this limitation and the referral patterns to our tertiary centre for diabetic pregnancies. Our conclusions on IGF-1 with preterm delivery may thus be limited to diabetic women going through pregnancy at least to week 32 . 


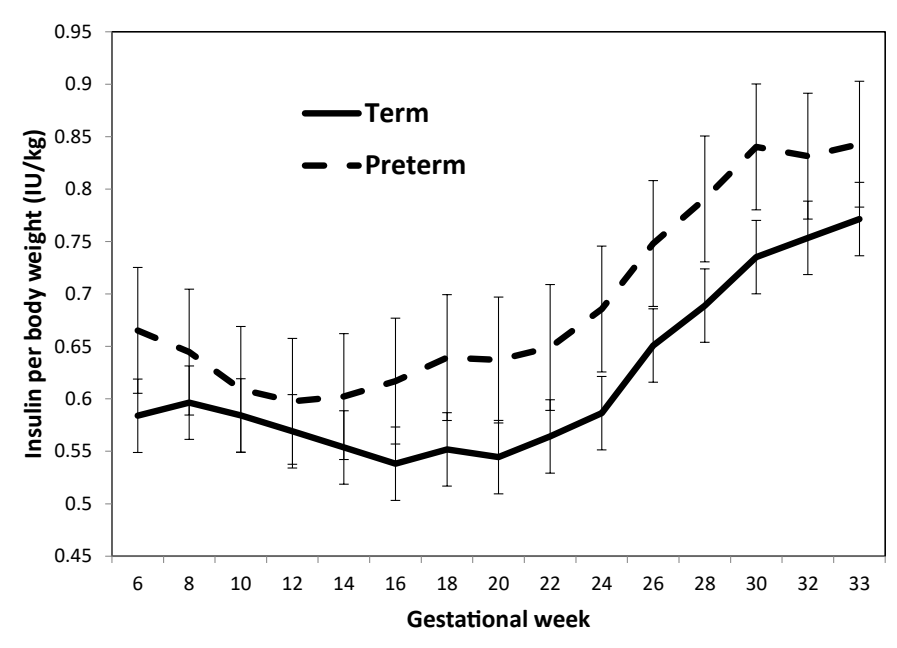

Data shown as mean and SEM

Figure 2. Insulin per body weight during pregnancy in 130 women with type 1 diabetes.

The findings are not easily explained by classical vasculopathy of diabetes. Preeclampsia and various degrees of nephropathy were not solely or decisively involved in preterm deliveries and the neonates tended to be more macrosomic than SGA (Table 1). The finding of an association between birth weight and IGF-1 would support the notion of similar mechanism in diabetic pregnancy, too, if reflected in data obtained early in pregnancy. This time interval, however, only displayed association with preterm delivery in our series (Table 2). Thus, growth restriction was not part of preterm delivery in diabetic pregnancy and, consequently, underdiagnosis of growth inhibiting factors seems unlikely.

We found an indication that insulin resistance may play a part in setting the stage for preterm delivery. The insulin doses were unanimously higher to achieve similar glycemic regulation in the preterm delivering women; albeit, this did not reach significance except for a limited time span. We may have found a potential modifying variable in the slight hyperinsulinemia as higher insulin may inhibit maternal IGF-1 secretion in the liver and indicate presence of some insulin resistance. In our efforts to find incipient nephropathy in AASI, AER, eye and paraclinical examinations we may still have missed some other factors. The growth hormone, which stimulates secretion of IGF-1, may also be involved with insulin resistance during pregnancy together with other hormonal substances like placental growth factor, activin A, and fibronectin $[7,8,16,17]$. These have all been proposed as predictors for preeclampsia, which is the single most common cause of preterm delivery.

IGF-1 is influenced in secretion and clearance by renal impairment either due to nephropathy or preeclampsia and its secretion is suppressed by insulin, whose clearance, again, is affected by renal function. Several studies provide evidence that high AER may trigger adverse pregnancy outcome, but the cause may not be diabetes in itself and our findings with a mixed diabetes population add to this argument [11]. As for insulin doses and glycemia, preterm delivery was improved insignificantly in two smaller studies on continuous subcutaneous insulin infusion comparing with the multiple injection regimens, which we started in the women $[9,18-21]$. However, the treatment of previous unrecorded glycemic fluctuations may help improve the obstetric outcome on many aspects including preterm deliveries and more appropriate growth patterns of the neonates. Overinsulinization of previously poorly controlled diabetes may attribute to a $1^{\text {st }}$ trimester decline in insulin requirement $[22,23]$. Thus, numerous hormonal and growth effects on delivery may be acting simultaneously in diabetic pregnancy.

In conclusion, preterm delivery showed an association with consecutive IGF-1 levels from week 14 to 32 and further studies are needed for confirmation.

\section{References}

1. Juul A (2003) Serum levels of insulin-like growth factor I and its binding proteins in health and disease. Growth Hormone \& IGF Research 13: 113-170.

2. Hiden U, Glitzner E, Hartmann M, Desoye G (2009) Insulin and the IGF system in the human placenta of normal and diabetic pregnancies. J Anat 215: 60-68. [Crossref]

3. Kirkegaard I, Uldbjerg N, Oxvig C (2010) Biology of pregnancy-associated plasma protein-A in relation to prenatal diagnostics: an overview. Acta Obstet Gynecol Scand 89: 1118-1125.

4. Kirkegaard I, Henriksen TB, Tørring N, Uldbjerg N (2011) PAPP-A and free B-hCG measured prior to 10 weeks is associated with preterm delivery and small-forgestational-age infants. Prenat Diagn 31: 171-175.

5. Canini S, Prefumo F, Pastorino D, Crocetti L, Afflitto CG, et al. (2008) Association between birth weight and first-trimester free beta-human chorionic gonadotropin and pregnancy-associated plasma protein A. Fertil Steril 89: 174-178. [Crossref]

6. Cooley SM, Donnelly JC, Geary MP, Rodeck CH, Hindmarsh PC (2010) Maternal insulin-like growth factors 1 and 2 (IGF-1, IGF-2) and IGFBP-3 and the hypertensive disorders of pregnancy. J Matern Fetal Neonatal Med 23: 658-661.

7. Kocyigit Y, Bayhan G, Atamer A, Atamer Y (2004) Serum levels of leptin, insulin-like growth factor-I and insulin-like growth factor binding protein-3 in women with preeclampsia, and their relationship to insulin resistance. Gynecol Endocrinol 18: 341-348.

8. Halhali A, Tovar AR, Torres N, Bourges H, Garabedian M, et al. (2000) Preeclampsia is associated with low circulating levels of insulin-like growth factor I and 1,25-dihydroxyvitamin $\mathrm{D}$ in maternal and umbilical cord compartments. $J$ Clin Endocrinol Metab 85: 1828-1833.

9. Farrar D, Tuffnell DJ, West J, West HM (2016) Continuous subcutaneous insulin infusion versus multiple daily injections of insulin for pregnant women with diabetes. Cochrane Database Syst Rev 7: CD005542.

10. Ringholm L, Damm JA, Vestgaard M, Damm P, Mathiesen ER (2016) Diabetic nephropathy in women with preexisting diabetes: From pregnancy planning to breastfeeding. Curr Diab Rep 16: 12

11. Jensen DM, Damm P, Ovesen P, Mølsted-Pedersen L, Beck-Nielsen H, et al. (2010) Microalbuminuria, preeclampsia, and preterm delivery in pregnant women with type 1 diabetes: results from a nationwide Danish study. Diabetes Care 33: 90-94.

12. Abalos E, Duley L, Steyn DW (2014) Antihypertensive drug therapy for mild to moderate hypertension during pregnancy. Cochrane Database Syst Rev 2: CD002252.

13. Marsál K, Persson PH, Larsen T, Lilja H, Selbing A, et al. (1996) Intrauterine growth curves based on ultrasonically estimated foetal weights. Acta Paediatr 85: 843-8. doi:

14. Frystyk J, Dinesen B, Orskov H (1995) Non-competitive time-resolved immunofluorometric assays for determination of human insulin-like growth factor I and II. Growth Regul 5: 169-176. [Crossref]

15. Kuc S, Wortelboer EJ, Koster MP, de Valk HW, Schielen PC, et al. (2011) Prediction of macrosomia at birth in type-1 and 2 diabetic pregnancies with biomarkers of early placentation. BJOG 118: 748-754.

16. Madazli R, Kuseyrioglu B, Uzun H, Uludag S, Ocak V (2005) Prediction of preeclampsia with maternal mid-trimester placental growth factor, activin A, fibronectin and uterine artery Doppler velocimetry. Int J Gynaecol Obstet 89: 251-257.

17. Fuglsang J, Lauszus F, Flyvbjerg A, Ovesen P (2003) Human placental growth hormone, insulin-like growth factor I and -II, and insulin requirements during pregnancy in type 1 diabetes. J Clin Endocrinol Metab 88: 4355-4361.

18. Mello G, Biagioni S, Ottanelli S, Nardini C, Tredici Z, et al. (2015) Continuous subcutaneous insulin infusion (CSII) versus multiple daily injections (MDI) of rapidacting insulin analogues and detemir in type 1 diabetic (T1D) pregnant women. $J$ Matern Fetal Neonatal Med 28: 276-280.

19. Bruttomesso D, Bonomo M, Costa S, Dal Pos M, Di Cianni G, et al. (2011) Type 1 diabetes control and pregnancy outcomes in women treated with continuous subcutaneous insulin infusion (CSII) or with insulin glargine and multiple daily injections of rapid-acting insulin analogues (glargine-MDI). Diabetes Metab 37: 426-431. 
20. Talaviya PA, Saboo BD, Joshi SR, Padhiyar JN, Chandarana HK, et al. (2013) Pregnancy outcome and glycemic control in women with type 1 diabetes: a retrospective comparison between CSII and MDI treatment. Diabetes Metab Syndr 7: 68-71.

21. Chico A, Saigi I, García-Patterson A, Santos MD, Adelantado JM, et al. (2010) Glycemic control and perinatal outcomes of pregnancies complicated by type diabetes: influence of continuous subcutaneous insulin infusion and lispro insulin. Diabetes Technol Ther 12: 937-945.
22. Damm P, Mersebach H, Råstam J, Kaaja R, Hod M, et al. (2014) Poor pregnancy outcome in women with type 1 diabetes is predicted by elevated HbAlc and spikes of high glucose values in the third trimester. J Matern Fetal Neonatal Med 27: 149-154.

23. Jovanovic L, Knopp RH, Brown Z, Conley MR, Park E, et al. (2001) Declining insulin requirement in the late first trimester of diabetic pregnancy. Diabetes Care 24: $1130-1136$.

Copyright: $\odot 2017$ Lauszus FF. This is an open-access article distributed under the terms of the Creative Commons Attribution License, which permits unrestricted use, distribution, and reproduction in any medium, provided the original author and source are credited. 